\section{Consequências da judicialização das políticas de saúde: custos de medicamentos para as mucopolissacaridoses}

\author{
Consequences of the judicialization of \\ health policies: the cost of medicines \\ for mucopolysaccharidosis
}

Debora Diniz 1,2

Marcelo Medeiros 2

Ida Vanessa D. Schwartz 3,4

\footnotetext{
1 Anis - Instituto de Bioética Direitos Humanos e Gênero, Brasília, Brasil.

2 Universidade de Brasília, Brasília, Brasil.

3 Serviço de Genética Médica, Hospital de Clínicas de Porto Alegre, Porto Alegre, Brasil. 4 Universidade Federal do Rio Grande do Sul, Porto Alegre, Brasil.

Correspondência D. Diniz

Anis Instituto de Bioética Direitos Humanos e Gênero. C. P. 8011, Setor Sudoeste, Brasília, DF 70673-970, Brasil. d.diniz@gmx.com
}

\begin{abstract}
This study analyzes expenditures backed by court rulings to ensure the public provision of medicines for treatment of mucopolysaccharidosis (MPS), a rare disease that requires high-cost drugs not covered by the Brazilian government's policy for pharmaceutical care and which have disputed clinical efficacy. The methodology included a review of files from 196 court rulings ordering the Brazilian Ministry of Health to provide the medicines, in addition to Ministry of Health administrative records. According to the analysis, the "judicialization" of the health system subjected the Brazilian government to a monopoly in the distribution of medicines and consequently the loss of its capacity to manage drug purchases. The study also indicates that the imposition of immediate, individualized purchases prevents obtaining economies of scale with planned procurement of larger amounts of the medication, besides causing logistic difficulties in controlling the amounts consumed and stored. In conclusion, litigation results from the lack of a clear policy in the health system for rare diseases in general, thereby leading to excessive expenditures for MPS treatment.
\end{abstract}

Jurisprudence; Mucopolysaccharidoses; Health Policy

\section{Introdução}

Os estudos com evidência empírica sobre judicialização da política de saúde no Brasil indicam que o principal bem judicializado nas cortes são os medicamentos 1,2 . A política de assistência farmacêutica apresenta uma série de desafios quanto ao desenho, à operacionalização, à atualização das listas, à ausência de instâncias recursais, à celeridade nas decisões, à articulação com outras esferas de fiscalização e ao registro. Esses desafios podem se caracterizar como falhas da política ou mesmo entraves à compreensão da política para sua operacionalização nas diferentes esferas do poder público, o que pode resultar na judicialização como um recurso para a garantia do justo em saúde. No conjunto do que se conhece como judicialização da saúde, há também a judicialização de outros bens, ou seja, casos em que o indivíduo procura as cortes para garantir seu acesso a serviços ou cuidados fundamentais do Sistema Único de Saúde (SUS). Não se devem confundir os bens judicializados (tecnologias, serviços ou cuidados), pois apontam para fenômenos diferentes nas cortes.

No subconjunto da judicialização de medicamentos estão as demandas por acesso a medicamentos de alto custo. Há várias motivações dos indivíduos e das associações para essa judicialização: desde a não incorporação do medicamento pela política, mas sua oferta no mercado; 
a inclusão do medicamento na política, mas sem a garantia de acesso; até mesmo o requerimento de medicamentos em fases ainda experimentais de pesquisa clínica, sob forte atuação da indústria farmacêutica. A depender da motivação original do indivíduo que judicializa e das razões apresentadas para a demanda, é possível qualificar os requerimentos como reparações justas de omissões da política ou interferências indevidas do Judiciário na execução da política. Os medicamentos de alto custo estão entre os que mais provocam os sentidos da justiça por causa de seu impacto financeiro, mas também porque, regra geral, têm como objeto da demanda novas tecnologias de saúde, algumas ainda sem o devido registro e avaliação no país.

Este artigo analisa a dimensão financeira da judicialização dos três medicamentos de alto custo disponíveis no mercado farmacêutico para o tratamento das mucopolissacaridoses (MPS) tipos I, II e VI, doenças genéticas raras, no Brasil. Foram analisados 196 processos com sentença favorável em ações determinando que o Ministério da Saúde fosse corresponsabilizado no pedido de provimento do medicamento no período entre 2006 e 2010. Como se trata de medicamentos de alto custo, não listados no dispensário público, acredita-se que as ações analisadas correspondam à quase totalidade do universo da judicialização dos medicamentos para as MPS no Brasil, envolvendo o Ministério da Saúde até janeiro de 2011. Nesta pesquisa foram recuperados 196 dossiês relativos a 195 pacientes. Dados da Associação Paulista de Mucopolissacaridose indicam que poucos indivíduos com a doença não estão nesse grupo, pois têm acesso ao medicamento no Estado de São Paulo, sem a corresponsabilização da União. Segundo dados atualizados em julho de 2011 pelo sistema web do Departamento de Informática do SUS (DATASUS), 245 indivíduos recebem os medicamentos por determinação judicial: 34 para MPS I (laronidase), 90 para MPS II (idursulfase) e 121 para MPS VI (galsulfase).

As MPS e seu tratamento possuem características que as tornam referência para a pesquisa sobre judicialização de medicamentos: (1) a judicialização se concentra em três medicamentos (laronidase, idursulfase e galsulfase); (2) esses são medicamentos de alto custo e fora da política de assistência farmacêutica; (3) cada medicamentos é produzido por uma única empresa farmacêutica; (4) a população de pessoas vivendo com MPS é pequena no país; (5) as MPS são doenças degenerativas, crônicas e com diagnóstico usualmente realizado na infância; (6) poucos países oferecem esses medicamentos no serviço público de saúde, como é o caso do Reino Unido ${ }^{3 ;}$ (7) as MPS são uma das doenças citadas como caso paradigmático para o fenômeno da judicialização no país, pelo volume de recursos movimentados em cada ação e pelo tamanho reduzido da população ${ }^{4}$. Além disso, as MPS provocam a discussão sobre a pertinência de políticas de saúde específicas para as doenças raras, bem como de critérios particulares para a inclusão ou não de medicamentos e tratamentos no SUS.

As MPS são doenças genéticas raras, hereditárias, causadas pela atividade deficiente de uma das enzimas envolvidas no catabolismo (“degradação”) dos glicosaminoglicanos (antigamente denominados mucopolissacarídeos) ${ }^{5}$. Os glicosaminoglicanos são constituintes de todas as células dos indivíduos. Nas MPS, que podem envolver o sistema nervoso central, ocorre o acúmulo progressivo dessas substâncias no meio intracelular e os indivíduos passam a apresentar, em graus variáveis, alterações faciais, oculares, auditivas, cardiopulmonares, articulares e esqueléticas. Como as manifestações clínicas iniciam na infância e a expectativa de vida costuma ser reduzida, a maioria dos pacientes é composta por crianças ou adolescentes 5,6.

As MPS são classificadas, de acordo com a enzima que está deficiente, em 11 tipos (I, II, IIIA, IIIB, IIIC, IIID, IVA, IVB, VI, VII e IX). Cada tipo corresponde a uma doença diferente e pode ser também categorizado de acordo com a gravidade da sintomatologia apresentada. Embora existam diferenças clínicas entre os tipos de MPS, as onze doenças classificadas dentro desse grupo apresentam semelhanças entre si, salientando-se o fato de elas serem multissistêmicas, progressivas, passíveis de estigmatização em razão dos efeitos físicos e de ocasionarem grande morbimortalidade aos afetados. Há medicamentos específicos somente para a MPS I (laronidase), a MPS II (idursulfase) e a MPS VI (galsulfase). A laronidase, a idursulfase e a galsulfase são enzimas artificiais, produzidas por engenharia genética, semelhantes às enzimas que estão deficientes nos pacientes.

De maneira geral, pode-se considerar que há evidências de benefício e de segurança dos medicamentos para as MPS I, II e VI, com terapia de reposição enzimática baseada em ensaios clínicos duplo-cegos randomizados contra placebo 7,8,9. Os benefícios incluiriam diminuição da hepatoesplenomegalia e melhora da função pulmonar, da capacidade de andar e da mobilidade articular dos pacientes. Isso significa que as melhores evidências disponíveis indicam potencial de reversão parcial da sintomatologia preexistente, mas não de prevenção ou de estabilização. Entretanto, a magnitude do benefício, pelo menos do ponto de vista da significância clínica, parece pequena. 
Há posições contra e a favor da incorporação desses medicamentos para fornecimento público do SUS. Os argumentos predominantes na oposição à incorporação têm origens diversas e podem ser resumidos em cinco: (1) o número de indivíduos incluídos nos ensaios clínicos é pequeno; (2) os ensaios clínicos existentes avaliaram um grupo específico de pacientes com MPS I, II ou VI (geralmente indivíduos com idade superior a 5 anos e com fenótipo mais brando), não sendo possível concluir se os seus achados podem ser extrapolados, por exemplo, para as demais faixas etárias ou para fenótipos mais graves; (3) não existem evidências sobre o aumento, associado ao uso dos medicamentos, da sobrevida dos pacientes; (4) não há evidências consistentes da melhora da qualidade de vida dos pacientes; (5) embora não existam estudos publicados sobre o custo-efetividade de tais medicamentos, é de se supor que os mesmos não sejam custo-efetivos, porque são de muito alto custo e porque a magnitude do seu efeito parece pequena.

\section{Metodologia}

A pesquisa foi realizada nos arquivos físicos e eletrônicos do Ministério da Saúde, prioritariamente na seção Demanda Judicial. Nessa seção encontram-se arquivados os dossiês que contêm as peças dos processos judiciais em que o ministério foi indiciado como corresponsável pelo provimento de bem requerido pelo paciente em juízo. O levantamento dos dossiês foi feito em duas fases. A primeira foi no arquivo eletrônico, que registra dados do demandante e do bem judicializado. As palavras-chave de busca para a pesquisa eletrônica foram: MPS, galsulfase, laronidase e idursulfase. Na segunda, foram recuperados 196 dossiês impressos entre fevereiro de 2006 e dezembro de 2010, correspondendo à demanda de 195 indivíduos (há um indivíduo com dois processos judiciais registrados em dois dossiês no ministério), cujo objeto de litígio era um dos três medicamentos para o tratamento da MPS. Em 2006, ocorreu o primeiro processo com registro eletrônico de litígio para a doença, o que não quer dizer que esta seja a primeira ação judicial. Os dossiês foram lidos e analisados na íntegra. $\mathrm{O}$ arquivamento dos registros de processos judiciais é parte da atividade da Consultoria Jurídica do Ministério, que considera o total de 196 casos como o universo da judicialização dos medicamentos para MPS que alcançou o ministério até dezembro de 2010. Não foram consultados dados sobre ações judiciais interpostas contra outros entes da Federação.
A análise dos dados foi realizada em sala reservada no MS. Os dados foram registrados em formulário eletrônico com 36 perguntas estruturadas e 2 perguntas abertas. O MS possui um sistema próprio de registro e sistematização dos dados de processos judiciais em que participa como réu. Neste trabalho, os dados sistematizados pelo ministério foram cotejados aos coletados dos dossiês diretamente pela equipe de pesquisa, como forma de checagem. Em caso de discordância entre os dois registros, optou-se pelo registro realizado pela equipe de pesquisadoras. A única variável que não foi recuperada diretamente pela equipe foi a de volume de recursos financeiros e quantidade de medicamentos destinados a cada paciente. Não há como verificar esses dados nos dossiês, uma vez que o rito de aquisição do medicamento percorre diferentes estágios e unidades dentro do ministério.

Há quatro rubricas gerais provocadas pela solicitação de compra de um medicamento: valor de aquisição (valor pago ao fornecedor do medicamento), valor de publicação (referente às custas de publicação do processo judicial), valor aduaneiro (correspondente à importação do medicamento) e valor de transporte do medicamento até a localidade do requerente. Para fins de orçamento gasto na judicialização, o Ministério da Saúde considera como valor total a soma dos custos de aquisição, publicação, importação e transporte desde a primeira aquisição com a sentença judicial até dezembro de 2010, data em que foram extraídos os dados, ou até o encerramento do fornecimento em caso de óbito do paciente (10 casos). Esse dado final relativo a cada indivíduo foi calculado e informado pelo ministério à pesquisa por meio do sistema de acesso web do DATASUS.

Os preços em várias partes deste estudo foram padronizados em uma escala comum, para permitir a comparação dos valores dos três medicamentos. A padronização foi feita por medicamento, tomando como valor de base o menor preço efetivamente pago pelo SUS quando a aquisição foi determinada judicialmente. Os preços não foram deflacionados e os valores correspondem aos constantes nos registros administrativos de compra do Ministério da Saúde entre 2006 e 2010, período da pesquisa.

As quantidades recomendáveis para tratamento variam conforme o medicamento, portanto é previsível que as quantidades judicializadas também variem. A indicação do medicamento depende do tipo de MPS que o paciente apresenta (laronidase para MPS I, idursulfase para MPS II, galsulfase para MPSVI) e do seu peso (0,58mg/ kg/infusão para MPS I; 0,5mg/kg/infusão para MPS II; e $1 \mathrm{mg} / \mathrm{kg} /$ infusão para MPS VI). Inde- 
pendentemente da MPS, as infusões são realizadas, sempre, uma vez por semana. Além disso, deve-se levar em conta que a quantidade de medicamento por frasco varia de MPS para MPS (laronidase: cada frasco tem $5 \mathrm{~mL}$ e cada $5 \mathrm{~mL}$ têm 2,9mg de medicamento; idursulfase: cada frasco tem $3 \mathrm{~mL}$ e cada $3 \mathrm{~mL}$ têm $6 \mathrm{mg}$ do medicamento; galsulfase: cada frasco tem $5 \mathrm{~mL}$ e cada $5 \mathrm{~mL}$ têm $5 \mathrm{mg}$ do medicamento). Para analisar simultaneamente as três distribuições de quantidades de medicamento adquiridas por indivíduo, estas quantidades foram padronizadas tendo como base a menor quantidade adquirida sob determinação judicial.

\section{Resultados}

Sujeição a monopólios de distribuição dos medicamentos

Monopólios de distribuição controlam preços, que tendem a ser mais altos do que os praticados em mercados concorrenciais. Nem sempre é possível evitar monopólios de distribuição, em particular no caso de medicamentos que muitas vezes são monopolizados em função da proteção de suas patentes ou, no caso específico das MPS, por serem medicamentos órfãos.
Um comprador de grande porte, como o Estado, tem alguma flexibilidade para negociar preços com monopólios quando a aquisição de medicamentos é feita dentro de seu planejamento orçamentário. A judicialização, porém, determina a aquisição obrigatória e imediata de determinadas quantidades dos medicamentos, sem licitação. Isso afasta qualquer planejamento e negociação, que, no caso das compras públicas, são regidos por princípios fixos destinados a garantir que a administração pública faça bons negócios. A sujeição a monopólios de distribuição, portanto, tende a implicar custos totais mais altos para as políticas de saúde. Esse, por sinal, é um argumento comum nas análises que criticam a judicialização.

A Tabela 1 apresenta evidências de sujeição do governo brasileiro a monopólio na aquisição judicializada de medicamentos de alto custo para MPS. Cerca de $97 \%$ da despesa judicializada são feitas com um único distribuidor, a Uno Healthcare Inc., uma empresa especializada em uma carteira restrita de medicamentos de alto custo em fase ainda experimental, e que tem o Estado brasileiro como o seu maior comprador: mais de R\$ 213 milhões em medicamentos para MPS foram comprados desta empresa ao longo de cinco anos (2006-2010). O valor total das compras feitas pelo governo brasileiro junto a essa

Tabela 1

Gastos com medicamentos segundo distribuidor. 2006-2010.

\begin{tabular}{|c|c|c|}
\hline Distribuidor/Medicamento & Total (R\$) & Total (\%) \\
\hline \multicolumn{3}{|l|}{ Uno healthcare } \\
\hline Galsulfase & 122.822 .336 & 100 \\
\hline Idursulfase & 86.985 .457 & 100 \\
\hline Laronidase & 3.372 .334 & 36 \\
\hline Subtotal & 213.180 .127 & 97 \\
\hline \multicolumn{3}{|l|}{ Genzyme } \\
\hline Galsulfase & 0 & 0 \\
\hline Idursulfase & 0 & 0 \\
\hline Laronidase & 5.890 .646 & 64 \\
\hline Subtotal & 5.890 .646 & 3 \\
\hline \multicolumn{3}{|l|}{ Não informado } \\
\hline Galsulfase & 593.703 & 0 \\
\hline \multicolumn{3}{|l|}{ Total } \\
\hline Galsulfase & 123.416 .039 & 56 \\
\hline Idursulfase & 86.985 .457 & 40 \\
\hline Laronidase & 9.262 .981 & 4 \\
\hline Total geral & 219.664 .476 & 100 \\
\hline
\end{tabular}

Fonte: Departamento de Informática do SUS e processos judiciais do arquivo do Ministério da Saúde. 
empresa é ainda maior do que os R \$ 213 milhões, pois além dos três medicamentos relacionados às MPS a Uno Healthcare Inc. vende uma série de outros medicamentos e materiais médicos de custo expressivo - alguns deles também objeto de judicialização, como microcatéteres e enzimas para o tratamento de outras doenças raras, como a doença de Gaucher. Os 3\% restantes têm sua aquisição computada como tendo sido feita junto à Genzyme Corporation, uma subsidiária do grupo farmacêutico Sanofi-Aventis.

No caso das MPS, pelo menos $97 \%$ das compras são feitas na empresa que monopoliza esse mercado no Brasil, pois distribui duas das três enzimas analisadas. A enzima cuja distribuição é compartilhada por duas empresas é aquela de menor relevância no custo total, a laronidase. Trata-se de um monopólio estrito desse mercado específico. Para o sistema de saúde brasileiro, uma consequência da determinação judicial de compra em um mercado monopolizado é a perda da capacidade plena de administrar os preços de aquisição.

\section{Perda da capacidade de administrar compras}

As aquisições planejadas conferem ao sistema de saúde poder de monopsônio. Medicamentos protegidos por patentes e medicamentos órfãos garantem a distribuidores monopolistas grande poder em relação a consumidores atomizados. No entanto, quando compras são administradas por uma agência única, esse monopsônio permite à agência contrapor o controle sobre preços dos monopólios. Quando não pode definir diretamente os termos de aquisição de medicamentos, o sistema de saúde perde seu poder de monopsônio e, consequentemente, parte de sua capacidade de administrar compras. Mas, ainda assim, é esse sistema que precisa arcar com os custos finais de aquisição dos medicamentos judicializados.

A consequência imediata da perda de capacidade de administração é uma elevação dos custos acima dos valores mínimos possíveis. Além da elevação dos custos de compra, o sistema de saúde fica sujeito a flutuações que, sob outras circunstâncias, dificilmente ocorreriam na mesma magnitude. Uma evidência dessas flutuações encontra-se na Figura 1, que apresenta a variação de preços médios por paciente de cada medicamento ao longo dos diferentes quantis (0\%-100\%) de aquisições judicializadas, tendo o menor preço médio como parâmetrobase (valor igual a 1). O que se analisa nesse gráfico não é se os preços praticados são os mínimos possíveis, mas o quanto eles flutuam acima do menor preço efetivamente obtido pelo
SUS. Assumindo que o menor preço médio por paciente efetivamente cobrado já é suficiente para remunerar produtores e distribuidores, qualquer flutuação acima desse valor representa majoração de preços.

Há grande variação de preços médios. Essa variação ocorre em todos os medicamentos, mas é particularmente maior no caso da galsulfase e da idursulfase. Nessas, mais de $70 \%$ dos preços médios por paciente correspondem a pelo menos o dobro do preço-base, chegando a $820 \%$ deste preço (o ponto nem sequer foi apresentado no gráfico para não prejudicar a visualização do conjunto). Esse não é um efeito decorrente de um preço isolado muito baixo e nem se refere a um único medicamento. Flutuações expressivas são observadas mesmo quando se utiliza uma base mais alta, a média dos dez menores preços médios obtidos por paciente, sendo o padrão estável nos dois medicamentos com distribuição integralmente monopolizada.

Uma parte pequena do comportamento dos preços deve estar relacionada a flutuações cambiais, pois trata-se de medicamentos importados. Porém, a hipótese mais plausível para a grande variação de preços é a impossibilidade do SUS negociar valores a partir de uma posição forte. Não se pode deixar de considerar, ainda, uma hipótese alternativa: a de que a eficiência em relação à escala das compras reduziria preços ou, em outras palavras, de que a flutuação de preços se explicaria porque os preços caem quando grandes quantidades são compradas. Como se verá adiante, essa é uma hipótese rejeitada pela evidência empírica disponível. Por fim, é possível considerar que as aquisições mais baratas estejam relacionadas a uma barganha própria da negociação ou a fatores externos, determinados por configurações específicas do lote, tais como a data de vencimento dos medicamentos.

\section{Ineficiência em relação à escala}

Operando sem grande poder de administrar compras e dentro de um mercado monopolizado, o SUS não alcança economias de escala que seriam esperáveis sob outras circunstâncias. Em um sistema de aquisições centralizado é de se esperar que a compra de um maior volume de um medicamento esteja relacionada a um maior poder de barganha e a uma série de economias que, em conjunto, reduzem preços finais. Mesmo na impossibilidade de ganhos expressivos, a compra em maior quantidade assegura, ao menos, a capacidade de manter estável e em níveis mais baixos a relação entre quantidades e preços. A aquisição fragmentada não permite esses ganhos. 


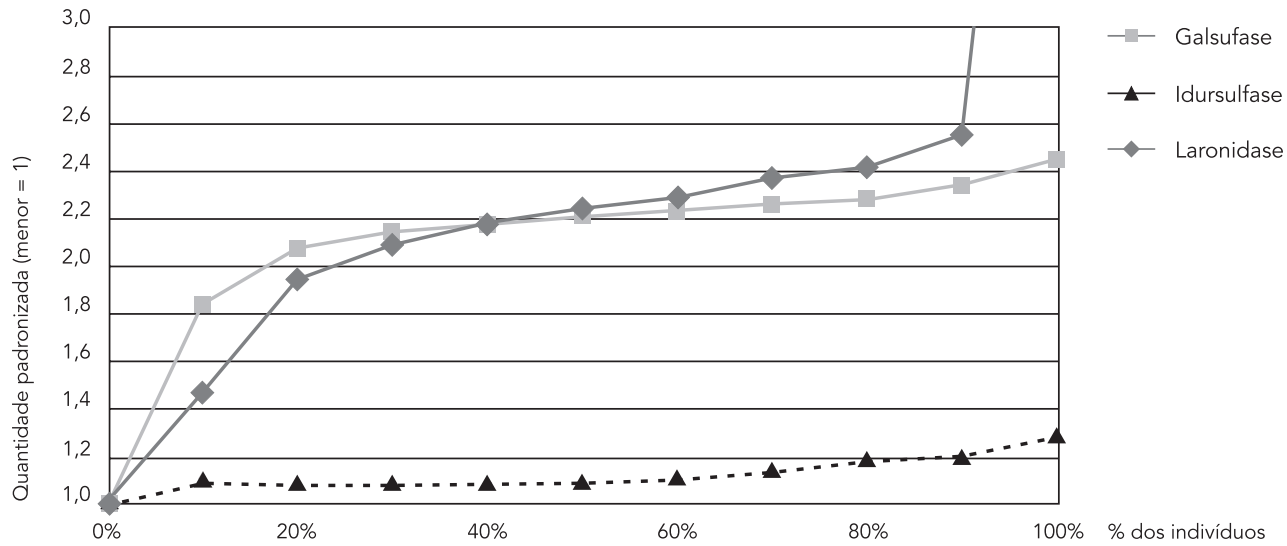

Fonte: Departamento de Informática do SUS e processos judiciais do arquivo do Ministério da Saúde.

Não dispomos de informações sobre cada compra realizada pelo SUS. Porém, como a judicialização induz aquisições individualizadas, as compras são feitas a cada oito meses (até janeiro de 2011 eram realizadas a cada seis meses) e o período analisado corresponde a cerca de dez ciclos de compras, tomamos como aproximação as quantidades adquiridas por paciente ao longo dos ciclos e seus respectivos preços unitários médios no período - isto é, o preço médio de uma unidade de medicamento adquirida para aquele paciente.

A Figura 2 apresenta a dispersão dos preços padronizados unitários médios por paciente (eixo vertical), segundo quantidades adquiridas (eixo horizontal) e retas de regressão linear preço-quantidade de cada medicamento. Preços padronizados com valor superior a três vezes o menor preço não são apresentados no gráfico, mas foram computados nas regressões. Se houvesse estabilidade de preços, seria de se esperar uma aglomeração dos pontos representando cada medicamento em torno de uma linha horizontal. Se houvesse economias de escala, essa linha seria inclinada para baixo, indicando que a aquisição de maiores quantidades permite a obtenção de menores preços. Nenhum desses comportamentos é observado.

Não existe correlação clara entre preços e quantidades de medicamentos. Os R2 das três regressões são muito baixos e não alcançam 0,04. A inclinação das retas de regressão, por sua vez, também não indica eficiências de escala na aqui- sição. Embora os sinais de dois dos coeficientes de regressão indiquem decréscimo de preço quando maiores quantidades são adquiridas, seus valores são mínimos e poderiam ser tratados como nulos até pelo menos a quarta casa decimal. A mais ajustada das regressões, referente à idursulfase, apresenta todos os coeficientes positivos, o que indica justamente o contrário do esperado - que os preços crescem na medida em que maiores quantidades são compradas (parâmetros não são apresentados na Figura 2).

Em suma, sob judicialização, as aquisições dos medicamentos de alto custo para MPS pelo SUS são, aparentemente, ineficientes em relação à escala. Essa interpretação deve ser tomada com cautela, pois baseia-se em indicadores aproximados, mas a evidência disponível sugere que as aquisições são feitas por preços instáveis, muito superiores aos mínimos possíveis e sem qualquer redução expressiva à proporção que aumentam as quantidades negociadas.

\section{Dificuldade de controle das quantidades consumidas e estocadas}

O SUS possui uma série de mecanismos para regular o uso de medicamentos dentro de níveis ao mesmo tempo eficazes para os tratamentos e eficientes para o sistema como um todo. Esses mecanismos visam, simultaneamente, a dois objetivos: eficácia médica e eficiência logística. A busca simultânea dos dois objetivos pode ser feita porque uma das características do SUS é a 
Relação entre preços padronizados e quantidades totais adquiridas.

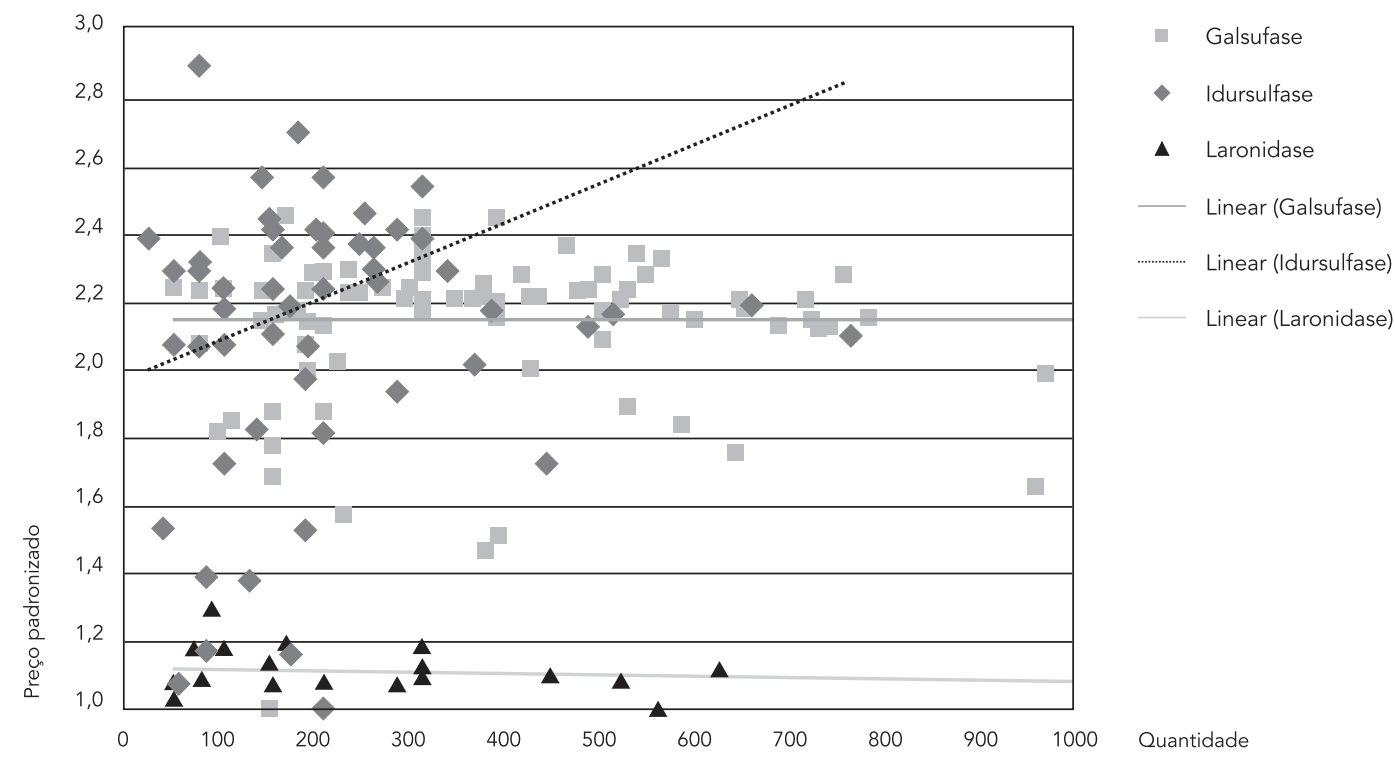

Fonte: Departamento de Informática do SUS e processos judiciais do arquivo do Ministério da Saúde.

elevada integração entre a indicação dos tipos e das quantidades de medicamentos, o seu consumo efetivo (postos de saúde e hospitais) e sua provisão (dispensários).

Quando o sistema tem controle sobre as quantidades adquiridas, utilizadas e estocadas, uma prescrição mais eficiente de medicamento de alto custo - por exemplo, doses menores eficazes - ou a interrupção da prescrição (por abandono do tratamento ou óbito) permite a realocação de medicamentos para outros indivíduos do sistema ou sua estocagem adequada para uso futuro. No caso da determinação judicial de compra, isso não é possível ou depende de arranjos externos à organização do sistema. Há indícios de que as organizações de pacientes com mucopolissacaridose sejam responsáveis por essas medidas realocativas de medicamentos em caso de óbito, por exemplo.

Entretanto, as quantidades acumuladas de medicamento adquiridas podem variar muito entre indivíduos. Há diversos fatores por trás dessas variações, como há quanto tempo o paciente recebe o medicamento e as diferenças de peso, que determinam as doses recomendadas. Independentemente desses fatores, cabe saber em que medida há concentração das quantidades adquiridas ao longo do tempo em certos indiví- duos. Para permitir a comparação das quantidades adquiridas dos três medicamentos, a Figura 3 mostra a distribuição das quantidades padronizadas segundo frações do total de aquisições. As quantidades são padronizadas tendo como base (valor 1) a menor porção adquirida, presumindo que a judicialização assegura, no mínimo, a compra das frações recomendadas para um indivíduo requerente.

Os resultados apresentados na Figura 3 merecem destaque. Pelo menos $60 \%$ das quantidades compradas são no mínimo cinco vezes maiores que o menor volume judicializado. No caso da galsulfase, $30 \%$ das aquisições são dez vezes maiores que a quantidade-base, com esta relação chegando, para os três medicamentos, a mais de 25 vezes no extremo da distribuição. Os medicamentos com maior desigualdade nas quantidades adquiridas são justamente aqueles com maior peso financeiro total. Isso indica que, além de elevadas desigualdades nos preços, há desigualdades substantivas nas frações distribuídas para cada indivíduo.

\section{Alocação desigual de recursos}

As concentrações de quantidades consumidas devem-se ao tempo de permanência no trata- 


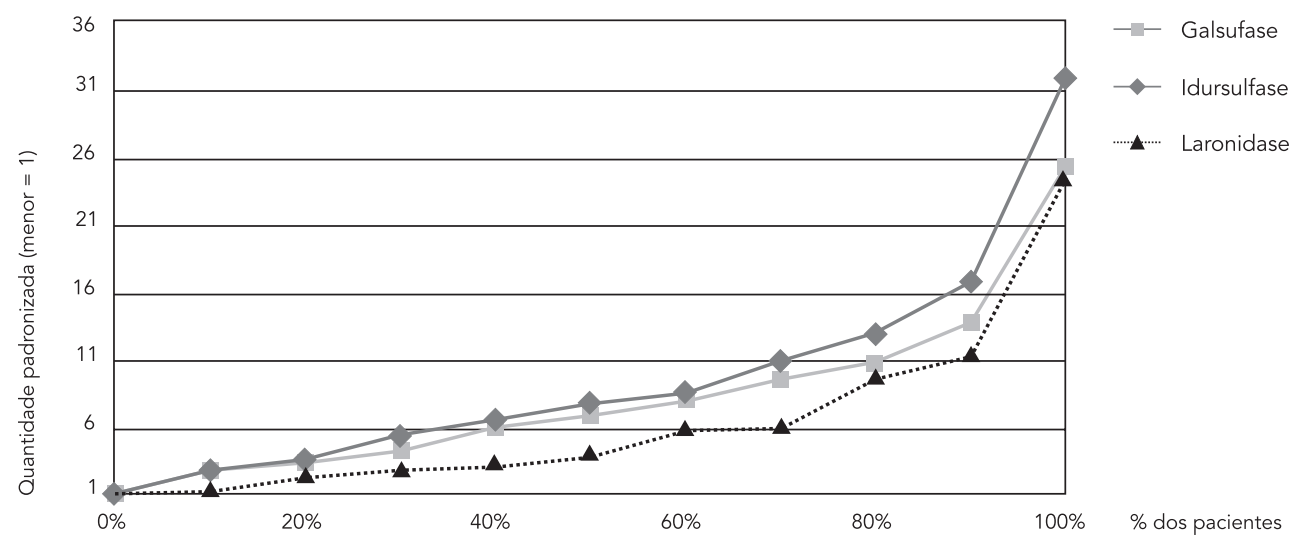

Fonte: Departamento de Informática do SUS e processos judiciais do arquivo do Ministério da Saúde.

mento e às doses recomendadas de acordo com o peso de cada paciente. Quando combinadas às concentrações de preços, as variações de quantidades provocam uma grande desigualdade na alocação de recursos, ainda que se referindo a um mesmo tipo de tratamento.

Os três medicamentos analisados têm custos diferentes, bem como são diferentes as populações por eles atendidas. Por definição, haverá desigualdades absolutas entre eles. Para uma descrição simultânea da concentração dos gastos com os três medicamentos, a Figura 4 trabalha apenas com desigualdades relativas e, para isto, distribui proporções do gasto acumulado, segundo proporções da população acumulada em três curvas de Lorenz.

As curvas de Lorenz indicam grande concentração dos gastos com medicamentos de alto custo em alguns indivíduos. A desigualdade é maior para a idursulfase e a laronidase, mas é também elevada no caso da galsulfase. No tocante à idursulfase e à laronidase, metade dos pacientes responde por cerca de apenas um quinto (20\%) do gasto total, ao passo que $10 \%$ dos pacientes no topo da distribuição consomem mais de $30 \%$ dos recursos. Na galsulfase, a distribuição é de $30 \%$ do gasto total na metade de processos de valor mais baixo e $20 \%$ dos recursos nos $10 \%$ de valor mais alto. Comparando-se os décimos extremos das distribuições ordenadas de indivíduos, essas desigualdades ficam mais evidentes: na galsulfase, os $10 \%$ com maiores gastos requerem mais de 35 vezes os recursos dos $10 \%$ com menores gas- tos e, nos dois outros medicamentos, a relação é de cerca de 50 vezes.

A elevada concentração dos gastos com a aquisição determinada judicialmente de medicamentos de alto custo para o tratamento das MPS sugere que os problemas distributivos dentro do SUS não se referem apenas à diferenciação entre os medicamentos de alto custo e os demais. Referem-se, também, a diferenciações de custos muito grandes dentro de um mesmo tratamento.

\section{Conclusão}

Este artigo analisou uma questão do subconjunto da judicialização de medicamentos - as ações judiciais de medicamentos de alto custo para um grupo específico de doenças genéticas raras que alcançaram o Ministério da Saúde entre 2006 e 2010. A judicialização dos medicamentos laronidase, idursulfase e galsulfase foi requerida por 195 indivíduos em 196 processos, com um custo total de R\$219.664.476, distribuídos da seguinte maneira: R\$ 9.262.981 para laronidase e 24 pacientes com MPS I; R\$ 86.985.457 para idursulfase e 68 pacientes com MPS II; e R\$ 123.416.039 para galsulfase e 103 pacientes com MPS VI (104 processos). Em todo o período, há uma concentração de indivíduos com MPS VI, portanto, uma maior demanda pelo medicamento galsulfase (53\%). Um em cada vinte pacientes foi a óbito durante o tratamento. 


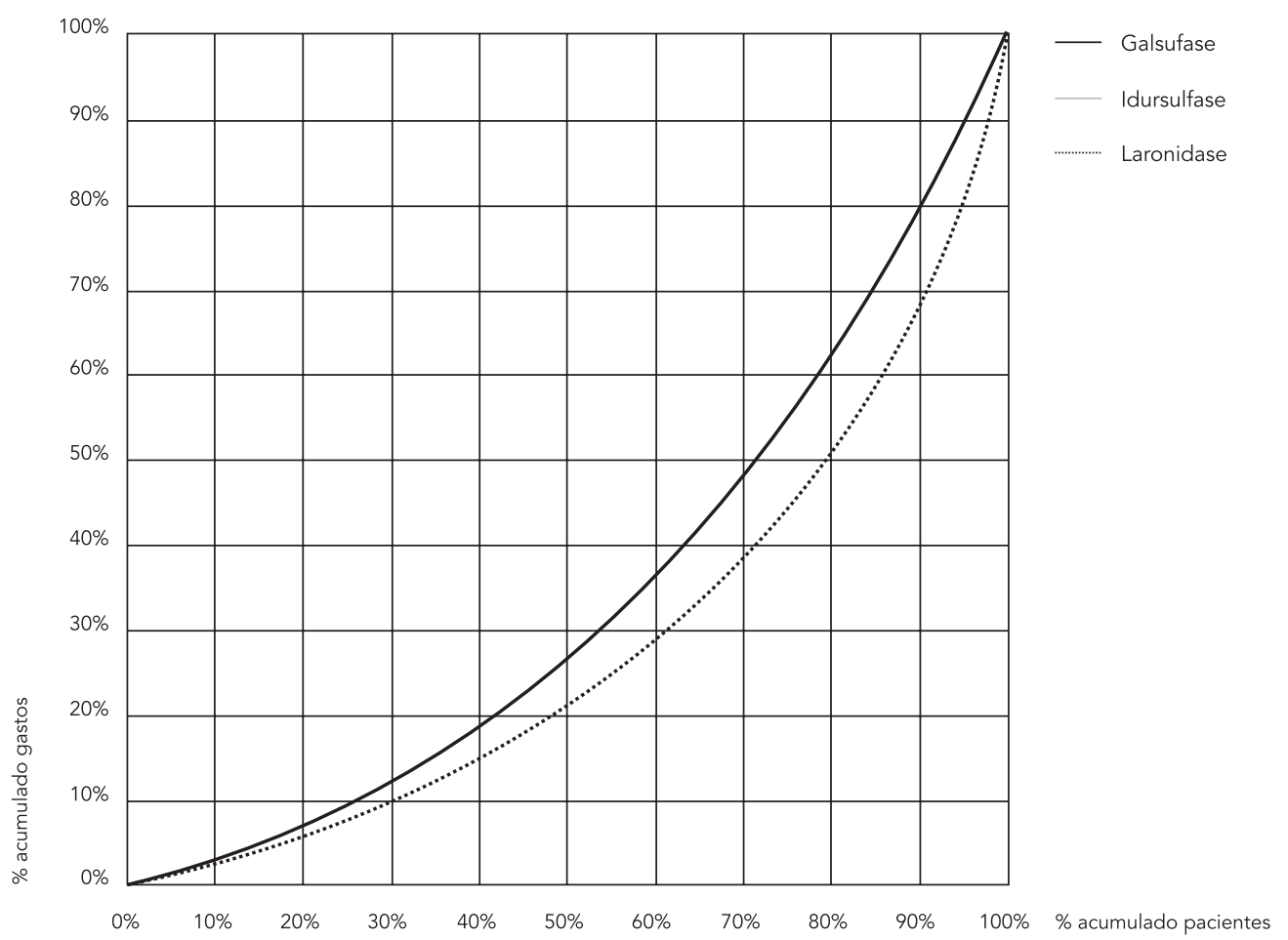

Fonte: Departamento de Informática do SUS e processos judiciais do arquivo do Ministério da Saúde.

Quase a totalidade (97\%) das compras do Ministério da Saúde foi realizada por intermédio de um mesmo distribuidor, a Uno Health Care Inc. Há variações entre os preços mínimos e máximos de cada frasco do medicamento no intervalo de tempo analisado: $28 \%$ para a laronidase; $716 \%$ para a idursulfase e $146 \%$ para a galsulfase. Não há como saber as razões para essas variações pelos dados analisados, sendo a hipótese mais razoável a perda da capacidade de controlar preços de compra pelo Ministério da Saúde devido à judicialização e à sujeição ao monopólio da distribuição dos medicamentos. Os limites mínimos de preço para cada aquisição podem ser ainda explicados por fatores específicos dos lotes, tais como a data de vencimento ou o tamanho da encomenda feita pelo ministério ao distribuidor. Muito embora razões específicas possam explicar os limites extremos nos preços das compras, os dados apontam para uma permanente oscilação nos valores pagos pelo Ministério da Saúde para a aquisição desses medicamentos em todo o período analisado. Se as compras fossem re- alizadas pela média dos cinco menores preços já pagos pelo ministério pelos três medicamentos, haveria uma economia de R\$ 84 milhões nos cinco anos de judicialização. É razoável imaginar que esse menor valor ainda seja superior ao que o governo poderia conseguir, caso os preços desses medicamentos fossem regulamentados pela Anvisa e caso eles fossem incluídos na política de fornecimento de medicamentos.

A judicialização resume a política de saúde à dispensação do medicamento de alto custo. Mesmo nos casos de demandas justas, a judicialização traz consequências econômicas para a organização da política. Duas delas foram analisadas neste artigo: a ineficiência em relação à escala e a dificuldade de controle das quantidades consumidas e estocadas. Em 2011, o Ministério da Saúde passou a adquirir os medicamentos em lotes a cada oito meses, na tentativa de garantir melhores preços aumentando o volume de aquisições. No entanto, o fluxo das ações judiciais é espontâneo, o que dificulta o controle de estoque da política. Os preços de compra dos medicamentos 
no período analisado não seguem padrões esperados de redução ou estabilidade com o aumento do volume de aquisição.

Além disso, dada a inexistência de uma política específica para doenças genéticas raras, ou mesmo dada a ausência de implementação da política de genética clínica no SUS, a assistência em saúde para os pacientes que judicializam é frágil. Informações coletadas por fontes complementares aos processos indicam que ausências importantes da política são supridas pela indústria farmacêutica. Um exemplo é a construção dos centros de infusão ou o treinamento de profissionais de saúde para a administração dos medicamentos. Outros arranjos informais são realizados para o armazenamento refrigerado permanente das enzimas ou para a redistribuição das remanescentes em casos de óbito do paciente.

A judicialização pode ser um instrumento de garantia de necessidades de saúde não satisfeitas. No caso dos três medicamentos para MPS analisados neste artigo, há incertezas quanto à relevância científica dos medicamentos para as necessidades reclamadas nas cortes. A definição sobre quais evidências científicas serão consi-

\section{Resumo}

O estudo analisa os gastos da judicialização de medicamentos para a mucopolissacaridose (MPS), uma doença rara, de alto custo, fora da política de assistência farmacêutica e com benefício clínico. O levantamento de dados foi realizado nos arquivos de 196 dossiês que determinou que o Ministério da Saúde fornecesse medicamentos no período entre 2006 e 2010, e nos registros administrativos e contábeis do Ministério da Saúde. A análise identifica sujeição do governo brasileiro a monopólios de distribuição de medicamentos e, consequentemente, perda de sua capacidade de administrar compras. Também identifica que a imposição da aquisição imediata e individualizada impede a obtenção de economias de escala com a compra planejada de maiores quantidades de medicamento, e impõe dificuldades logísticas para o controle das quantidades consumidas e estocadas. Conclui-se que a judicialização decorre da ausência de uma política clara do sistema de saúde para doenças raras em geral, e tem como consequência gastos acima do necessário para o tratamento.

Jurisprudência; Mucopolissacaridoses; Política de Saúde deradas suficientes para a incorporação de uma nova tecnologia em saúde não deve ser feita pelo Judiciário, mas pelos técnicos da política de saúde. Na ausência das razões explícitas para a não incorporação, os juízes acabam por definir que bens protegerão necessidades não satisfeitas, sob a tese da omissão ou da discriminação injusta da política contra as pessoas vivendo com doenças genéticas raras.

O Judiciário, no entanto, reduz a proteção das necessidades em saúde à garantia do medicamento: com a sentença favorável ao paciente, o Ministério da Saúde é obrigado a incluir o indivíduo no sistema de dispensação de medicamentos de alto custo. Diversos outros domínios da assistência em saúde são ignorados, tais como o armazenamento dos medicamentos, a administração das enzimas nos pacientes, o treinamento das equipes de saúde ou a definição de locais adequados para a infusão. Informações complementares recuperadas nesta pesquisa indicam que as indústrias farmacêuticas são as principais responsáveis pela organização desses outros domínios necessários para que o paciente se mantenha em tratamento.

\section{Colaboradores}

D. Diniz contribuiu no planejamento do estudo, análise dos dados, redação e revisão. M. Medeiros colaborou no planejamento do estudo, tratamento e análise estatística dos dados, redação e revisão. I. V. D. Schwartz contribuiu no planejamento do estudo, análise dos resultados, redação e revisão do texto.

\section{Agradecimentos}

Agradecemos a colaboração de Vanessa Carrião, Renata Brito e João Neves que realizaram a coleta e o processamento dos dados. 


\section{Referências}

1. Ventura M, Simas L, Pepe VLE, Schramm FR Judicialização da saúde, acesso à justiça e à efetividade do direito à saúde. Physis (Rio J.) 2010; 20:77-100.

2. Andrade E, Machado CD, Faleiros DR, Szuster DAC, Guerra Júnior AA, Silva GD, et al. A judicialização da saúde e a política nacional de assistência farmacêutica no Brasil: gestão da clínica e medicalização da justiça. Rev Méd Minas Gerais 2008; 18 (4 Suppl 4):S46-50.

3. Ultra orphan drugs for lysosomal storage disorders. 2009. http://www.specialisedservices.nhs. uk/library/22/A_Guideline_Comparison_and_ Survey_of_International_Current_Practice_in_Ul tra_Orphan_Drugs_for_Lysosomal_Storage_Disor ders.pdf (acessado em 31/Ago/2011).

4. Boy R, Schwartz IV, Krug BC, Santana-da-Silva LC, Steiner CE, Acosta AX, et al. Ethical issues related to the access to orphan drugs in Brazil: the case of mucopolysaccharidosis type I. J Med Ethics 2011; 37:233-9.

5. Neufeld E, Muenzer J. The mucopolysaccharidoses. In: Scriver CR, Beaudet AL, Sly WS, Valle D, editors. The metabolic and molecular basis of inherited disease. 7th Ed. New York: McGraw-Hill; 2001. p. 3421-52.
6. Vieira T, Schwartz I, Munoz V, Pinto L, Steiner C, Ribeiro M, et al. Mucopolysaccharidoses in Brazil: what happens from birth to biochemical diagnosis? Am J Med Genet 2008; 146A:1741-7.

7. Harmatz P, Giugliani R, Schwartz I, Guffon N, Teles EL, Miranda CS, et al. Enzyme replacement therapy for mucopolysaccharidosis IV: a phase 3 , randomized, double-blind, placebo controlled, multinational study of recombinant human n-acetilgalactosamine 4-sulfatase (recombinant human arylsulfatase B or RHASB) and follow-on open label extension study. J Pediatr 2006; 148:533-9.

8. Muenzer J, Wraith JE, Beck M, Giugliani R, Harmatz P, Eng CM, et al. A phase II/III clinical study of enzyme replacement therapy with idursulfase in mucopolysaccharidosis II (Hunter syndrome). Genet Med 2006; 8:465-73.

9. Wraith JE, Clarke LA, Beck M, Kolodny EH, Pastores GM, Muenzer J, et al. Enzyme replacement therapy for mucopolysaccharidosis i: a randomized, double-blinded, placebo-controlled, multinational study of recombinant human alpha-l-iduronidase (laronidase). J Pediatr 2004; 104:581-8.

Recebido em 02/Set/2011

Aprovado em 21/Nov/2011 